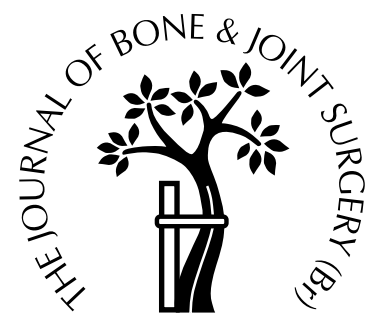

\title{
Incidence of clostridial contamination in donors' musculoskeletal tissue
}

\author{
T. I. Malinin, B. E. Buck, H. T. Temple, O. V. Martinez, W. P. Fox \\ From the University of Miami, USA
}

$\mathbf{R}$ eports of infection by Clostridium sordellii associated with allograft transplantation have generated considerable interest. We report our experience in recognising clostridial contamination in cadaver donors of musculoskeletal tissue. Tissues obtained from 795 consecutive donors were excised using standard surgical techniques. Samples of blood and bone marrow were also obtained. Donors with clostridia recovered from any site were matched with the preceding donor without clostridia as a procedural and environmental control. The histories of the donors were analysed to determine which variables had a relationship to contamination by running a contingency table and chi-squared test on the variables against the event of a donor being contaminated.

Sixty-four donors $(8.1 \%)$ had clostridia, most commonly $C$. sordellii. Clostridia were grown from the blood, marrow and tissue samples of 52, 37 and 30 donors, respectively. In eight cases, they were cultured from the tissue samples alone. There was no significant difference in age or gender between the contaminated donors and the control group. Open wounds were more common in control than in contaminated subjects, but only death by drowning in the contaminated group was statistically significant $(p=0.02)$. The time between death and the excision of tissue which was contaminated (16 hrs 10 mins) compared with control (11 hrs 10 mins) donors was also significant $\left(p<10^{-6}\right)$.

T. I. Malinin, MD, Professor of Orthopaedics and Rehabilitation B. E. Buck, MD, Clinical Associate Professor of Orthopaedics and Rehabilitation

H. T. Temple, MD, Professor of Orthopaedics and Rehabilitation

O. V. Martinez, PhD, Research Associate Professor of Orthopaedics and Rehabilitation

Tissue Bank, Department of Orthopaedics and Rehabilitation, University of Miami School of Medicine, PO Box 016960 (R-12), Miami, Florida 33101, USA.

W. P. Fox, PhD, Professor and Chairman

Department of Mathematics, Francis Marion University, 5130 East Palmetto, Florence, South Carolina 29506, USA.

Correspondence should be sent to Professor T. I. Malinin.

C)2003 British Editorial Society of Bone and Joint Surgery doi:10.1302/0301-620X.85B7.14438 \$2.00
We conclude that there is clostridial contamination in a significant number of tissue donors, particularly with increasing time between death and tissue excision. Among the most commonly encountered species is C. sordellii. Multiple microbiological cultures, including blood, are necessary in order to identify clostridial contamination.

J Bone Joint Surg [Br] 2003;85-B:1051-4.

Received 17 April 2003; Accepted 6 June 2003

A recent report of allograft-mediated infection has raised concerns about the transmission of microbial infections in musculoskeletal allografts. ${ }^{1}$ Of particular importance was a case of infection by Clostridium sordellii in the knee which resulted in the death of a young but otherwise healthy patient. ${ }^{2}$ For this reason the Centres for Disease Control and Prevention (CDC) has advised clinicians to consider Clostridium as an organism in patients with infection after an allograft procedure. ${ }^{3}$ Several other similar but non-lethal cases of clostridial infection associated with allografts have also been investigated by the CDC. A statement from the organisation which supplied an allograft contaminated with C. sordellii stated that this micro-organism is rarely encountered and that each tissue to be implanted cannot be directly tested microbiologically. ${ }^{4}$ Our experience indicates that this is not the case. $C$. sordellii is ubiquitous; under normal conditions it is found in the soil and as part of human intestinal flora. Its pathogenicity is related to its ability to produce lethal factors, originally known as toxins, which cause local necrosis, oedema, increased vascular permeability, haemorrhage and other pathological changes. ${ }^{5}$ The few infections with $C$. sordellii which have been described in the medical literature have mostly occurred in healthy young women. ${ }^{6,7}$ Infection in a young man after a deep laceration of the thigh has also been reported. ${ }^{8}$ Extensive microbiological studies of cadaver donors of musculoskeletal tissues have indicated that contamination with $C$. sordellii is not rare. ${ }^{9,10}$ Since infections of allografts by this organism have now been reported, surgeons must become aware of the nature and frequency of possible contaminations with this and related clostridia and the methods by which they can be detected. Our aim, therefore, was to report the incidence of clostridial contamination in a series of pre-screened consecutive 
donors of tissue and to describe the methods used to identify these micro-organisms.

\section{Materials and Methods}

Our study included 795 consecutive musculoskeletal donors from which tissues have been removed up to 24 hours after death. All donors with clostridia recovered from any anatomical site were identified. The medical histories of the donors were reviewed and a number of variables analysed in order to determine possible risk factors for the presence of clostridia, including age, gender, race, cause of death, the presence of wounds, stay in intensive care, the time interval between death and excision of tissue and the distance transported from the place of death to that of excision. The donors from which clostridia had been recovered were compared with those not harbouring these micro-organisms. The control group consisted of the preceding donor to the donor who was contaminated with clostridia. The social and medical histories of all donors were screened. ${ }^{11}$ Potential donors with a septicaemia or infections other than lobular pneumonia were excluded. In all instances, excision of aseptic tissue took place before the post-mortem which was subsequently performed to determine the suitability of the donor.

All excision of tissue was performed in the operating theatre of either the Tissue Bank or a hospital using standard surgical techniques by physicians, technicians and nurses trained in tissue banking. This gave uniformity and continuity of procedures throughout the period of the study. The donor's body was prepared in two stages. The regions of the body from which the tissues were to be excised were first washed with an antiseptic soap, and the hair was shaved. They were then scrubbed twice for seven minutes each with iodine scrub and rinsed with alcohol. The body was then placed on an operating table and again prepared with providone-iodine solution and draped in a sterile fashion. The perineal area was draped off separately. The body was then covered with either sterile plastic adhesive or disposable paper drapes. Incisions were made through these drapes. After the skin had been incised, the scalpel was discarded and the incision sprayed with iodine solution.

Cultures performed at procurement included blood samples from the vena cava collected by a catheter through the great saphenous vein which was exposed through a small incision in the proximal thigh. Blood samples were immediately injected into anaerobic and aerobic blood culture bottles (Columbia broth with SPOS and $\mathrm{CO}_{2}$ and Tripticase Soy Broth with SPS and $\mathrm{CO}_{2}$; Becton-Dickinson, Maryland). In addition, iliac bone marrow was obtained concomitantly by aspiration through a small incision made over the iliac crest and samples of 4 to $12 \mathrm{ml}$ were injected into anaerobic and aerobic blood culture bottles.

Samples from each excised bone and tissue were obtained and placed into thioglycolate medium $135 \mathrm{C}$ (Becton-Dickinson), pre-reduced by boiling. These consisted of superficial swabs, pieces of soft tissue, bone and/or
Table I. Clostridia infected donors recognised by site per year

\begin{tabular}{lllll}
\hline & $\begin{array}{l}\text { Number of } \\
\text { clostridium- } \\
\text { positive donors }\end{array}$ & Blood & $\begin{array}{l}\text { Bone- } \\
\text { marrow } \\
\text { aspirate }\end{array}$ & Tissues \\
\hline 1996 & 16 & 13 & 11 & 8 \\
1997 & 9 & 7 & 4 & 4 \\
1998 & 10 & 8 & 8 & 6 \\
1999 & 9 & 9 & 5 & 3 \\
2000 & 12 & 9 & 4 & 5 \\
2001 & 8 & 6 & 5 & 4 \\
Total positive for clostridia & 64 & 52 & 37 & 30 \\
Total negative for clostridia & & 12 & 27 & 34 \\
\hline
\end{tabular}

from each donor at the time of excision of the allografts. These were independent of samples taken subsequently during processing of the allografts.

The blood and marrow aspirate culture bottles were incubated at $35^{\circ} \mathrm{C}$ until growth occurred, or for up to seven days. Thioglycolate tubes were incubated at $35^{\circ} \mathrm{C}$ until growth occurred, or for 14 days. This period of time was chosen because some anaerobic micro-organisms manifest growth only after ten days of incubation. ${ }^{10}$

All primary cultures showing evidence of growth were subcultured onto agar media under anaerobic and aerobic conditions. All isolated organisms were identified by standard methods. 11

Statistical analysis. We recorded the relationship between discreet (categorical) variables, when one variable has $\mathrm{R}$ categories and the other has $\mathrm{C}$ categories, and used the chisquared test for an $\mathrm{R} \times \mathrm{C}$ contingency table. We ascribed statistical significance to $\mathrm{p}$ values $<0.05$.

\section{Results}

Of the 795 donors, 64 had positive cultures for clostridia. The mean number of donors having clostridia per year was 10.7 (8 to 16) representing $8.1 \%$ of the total cases (Table I).

The mean age for this group of donors was 44.8 years (14 to 68$)$. There were 50 men and 14 women, 59 were Caucasian $(92.1 \%)$, four were black $(6.3 \%)$, and one $(1.6 \%)$ of mixed race. Most $(51.6 \%)$ had died from atherosclerosis of the coronary arteries. Drowning (12.6\%) was the next most common cause of death. Other causes included gunshot wounds $(4.7 \%)$, blunt injuries $(4.7 \%)$, etc as shown in Table II.

The mean age of donors in the control group was 43.7 years (16 to 72 ). There were 53 men and 11 women. There was no statistically significant difference between the donors who were infected with clostridia and the control group in regard to age, gender, race, or distance transported for excision of tissue. The causes of death (17 types) were examined for significance. Drowning $(\mathrm{z}=1.97757$, $\mathrm{p}=0.0239$ ) was the only significant cause of death related to the isolation of clostridia. Only four (9.4\%) of those infected with clostridia and $13(20 \%)$ in the control group $(\mathrm{p}=0.01)$ had been in an intensive-care unit before death. 
Table II. Cause of death in 64 cadaver tissue donors who were culturepositive compared with 64 culture-negative donors for Clostridium species

\begin{tabular}{lll}
\hline Cause of death & $\begin{array}{l}\text { Number of } \\
\text { culture-positive } \\
\text { donors }(\%)\end{array}$ & $\begin{array}{l}\text { Number of } \\
\text { culture-negative } \\
\text { donors }(\%)\end{array}$ \\
\hline Coronary arteriosclerosis & $33(51.6)$ & $27(42.2)$ \\
Pulmonary embolism & $3(4.7)$ & $1(1.6)$ \\
Cerebrovascular disease & $2(3.1)$ & $6(9.4)$ \\
Gunshot wound & $3(4.7)$ & $11(17.2)$ \\
Drug overdose & $1(1.6)$ & $2(3.1)$ \\
Aortic aneurysm & $2(3.1)$ & $1(1.6)$ \\
Drowning & $8(12.6)$ & $2(3.1)$ \\
Electrocution & $1(1.6)$ & $0(0.0)$ \\
Asphyxia & $3(4.7)$ & $0(0.0)$ \\
Hanging & $3(4.7)$ & $0(0.0)$ \\
Motor-vehicle accident & $3(4.7)$ & $7(10.9)$ \\
Rheumatic heart disease & $1(1.6)$ & $1(1.6)$ \\
Ethanol poisoning & $1(1.6)$ & $1(1.6)$ \\
Unknown & $0(0.0)$ & $2(3.1)$ \\
Fall & $0(0.0)$ & $1(1.6)$ \\
Allergic reaction & $0(0.0)$ & $1(1.6)$ \\
Cancer & $0(0.0)$ & $1(1.6)$ \\
Total & $64(100.00)$ & $64(100.0)$ \\
\hline
\end{tabular}

Table III. Distribution of Clostridium species recovered from the blood, bone marrow and tissues

\begin{tabular}{lc}
\hline Organism & Number $(\%)$ \\
\hline C. bifermentans & $4(5.8)$ \\
C. butyricum & $7(10.1)$ \\
C. cadaveris & $1(1.4)$ \\
C. innocuum & $2(2.9)$ \\
C. perfringens & $5(7.2)$ \\
C. ramosum & $4(5.8)$ \\
C. septicum & $11(15.9)$ \\
C. sordellii & $26(37.7)$ \\
C. species, other & $8(11.6)$ \\
C. sporogenes & $1(1.4)$ \\
Total & 69 \\
\hline
\end{tabular}

Open wounds were present in seven donors with clostridia (10.9\%) and in $18(21.8 \%)$ of the control group. This difference was statistically significant $(p=0.03)$. The mean time interval between death and excision of tissue was 16 hours and 10 minutes ( $1 \mathrm{hr} 53 \mathrm{~min}$ to $24 \mathrm{hrs} 10 \mathrm{~min}$ ) in the clostridia group and 11 hours and 10 minutes in the control group (4 hrs $25 \mathrm{~min}$ to $23 \mathrm{hrs} 53 \mathrm{~min})\left(\mathrm{p}<10^{-6}\right)$. The distance which the donors were transported for excision of tissue from the place of death was not statistically significant between the two groups.

Of the 64 donors with clostridia, $52(81.3 \%)$ had positive blood cultures for these organisms, 37 (57.8\%) had positive bone-marrow aspirate cultures, and 30 (46.9\%) had positive cultures of tissue samples (Table I). The most common species of clostridia recovered was C. sordellii $(37.7 \%)$ followed by $C$. septicum (15.9\%) and C. butyricum (10.1\%) (Table III). The presence of a positive blood culture correlated with the post-mortem interval $(\mathrm{p}=0.000019)$, whereas no statistically significant relationship was observed between positive cultures in marrow or tissue and the post-mortem interval.

A single type of species of Clostridium was identified in 60 donors $(93.7 \%)$, two in three $(4.7 \%)$ and three in one $(1.6 \%)$. Of the 30 donors with clostridia at any tissue site, the pelvis was involved in $14(14 / 30,46.7 \%)$. Clostridia were cultured in multiple tissues in 13 donors (13/30, $43.3 \%$ ). In 12 cases they were identified only in the blood culture and in four only in the bone-marrow aspirate. In 22 (34.4\%) identification of clostridia from either blood or bone marrow was accompanied by their identification from one or more musculoskeletal tissue. In eight cases clostridia were identified only in tissue samples and in six of these, in three or fewer samples.

There was no significant change during the six-year period of this study with regard to the yearly number of donors, the number of donors who were infected with clostridia and the number recognised by type of culture (blood, bone marrow or tissue). Hence, no technical drift was recognised.

\section{Discussion}

Clostridia were isolated from 64 of 795 (8.1\%) musculoskeletal allograft donors. The most frequently identified species was C. sordellii (37.7\%). The isolation of clostridia from this group of donors was facilitated by culturing blood, bone-marrow and multiple tissue samples from bone, tendons, ligaments, fasciae, cartilage and joint capsules.

In the donors with clostridia, blood samples yielded the organisms most often (52 of 64 cases), followed by bonemarrow aspirates (37 of 64 cases). Donors with positive blood and/or bone-marrow cultures had clostridial contamination of bone or other tissues in about one-third of cases. Of the 64 cadavers with clostridia, only 30 had positive cultures of tissue. Therefore, if only bone and tissue were sampled, half of the cases contaminated with clostridia would not be recognised. Furthermore, if the number of samples from the tissues was reduced, it is likely that the recognition of contamination would also be reduced proportionately. Conversely, only $12.5 \%$ of cases had clostridia in tissues, but not in either blood or bone-marrow cultures. These figures demonstrate that cultures of blood and bone marrow have a high correlation with contamination of distant tissues, but also that sampling of all excised tissues is necessary in order to identify contamination with clostridia.

The origin of micro-organisms in blood from cadavers less than 24 hours after death has not been defined with certainty. It is not known whether microbial transmigration from the gastrointestinal tract occurs at death or later. ${ }^{12,13}$ That it does occur within two or more days of death is unquestionable. Since there is a discrepancy between the recovery of pathogens from post-mortem tissues and evidence of ante-mortem infection, routine sampling of blood and tissues from cadaver donors assumes paramount importance. ${ }^{13,14}$ If the concern is with potential contamination 
with micro-organisms from the gastrointestinal tract, sampling of blood from the inferior vena cava, a pool of blood closest to the intestines, appears to be logical. ${ }^{15}$ In our series, among the various tissues, the pelvic bones were the tissues which were most commonly contaminated by clostridia. This also supports the hypothesis that these organisms come from the gastrointestinal tract.

The only statistically significant difference between the uninfected donors from which clostridia were recovered and their counterparts was the time interval between death and excision of tissue. This again suggests post-mortem contamination. We could not identify any risk factors which would predict which donors would harbour clostridia. Among the causes of death, drowning was more often associated with contamination by clostridia and this difference was statistically significant $(\mathrm{p}=0.02)$. Thus, the only means by which these donors can be identified and either excluded from the donor pool or their tissues subjected to effective sterilisation is by extensive microbiological survey. The recent editorial note $^{1}$ concerning the limitations of aseptic excision and processing of allografts is not entirely accurate. Aseptic excision and processing of tissues have been practised in the USA long before secondary sterilisation became accepted. ${ }^{16-19}$ This practice continues currently with success. ${ }^{17,20,21}$ However, in order to safeguard the recipients of aseptically excised and processed allografts, extensive microbiological monitoring both of the donor and the allografts themselves is necessary. Thus, blood cultures appear to be as important as they are in a clinical setting. ${ }^{22}$ Allografts can easily be sampled during processing and before packaging. If they are to be sterilised secondarily, it seems appropriate to know which micro-organisms are being inactivated. The absence of the organisms which have been inactivated on post-sterilisation samples would indicate the effectiveness of sterilisation. Repeated recovery of the same organisms would indicate inadequate sterilisation.

Currently, some 750000 human tissue allografts are transplanted annually. ${ }^{1}$ Associated infections have been rare. Therefore, surgeons who use allografts may be confident of their safety if they can assure themselves of the adequacy of the screening and testing of donors and donor tissues. $^{20,21}$

Clostridial infections associated with allografts have heightened the awareness of the necessity for adequate microbiological screening of donors. Our experience suggests that to be effective, this screening requires the taking of multiple samples including those of the blood and bone marrow. ${ }^{23}$ The recognition of clostridia including C. sordellii in cadaver donor tissues is not new. ${ }^{9,10,12-14}$ The realisation of the potential contamination of allograft tissues with clostridia should emphasise the need for a comprehen- sive microbiological survey of cadaver donors of musculoskeletal tissues thus minimising or eliminating the chance of transmitting potentially lethal infections. ${ }^{24}$

No benefits in any form have been received or will be received from a commercial party related directly or indirectly to the subject of this article.

\section{References}

1. CDC. Septic arthritis following anterior cruciate ligament reconstruction using tendon allografts. Florida and Louisiana 2000; $M M W R$ 2001;50(48):1081-1083.

2. CDC. Notice to readers: Unexplained deaths following knee surgery. Minnesota, 2001; MMWR 50(46):1035-36.

3. CDC. Public Health Dispatch: Update: Unexplained deaths following knee surgery. Minnesota, 2001; MMWR 50(48): 1080.

4. Kurz A. CryoLife Inc, Letter, December 20, 2001, Kennesaw, GA.

5. Abdulla A, Yee L. The clinical spectrum of Clostridium sordellii bacteremia: two case reports and a review of the literature. J Clin Pathol 2000;53:709-12.

6. McGregor JA, Soper DE, Lovell G, Todd JK. Maternal deaths associated with Clostridium sordellii infection. Am J Obst Gynecol 1989;161:987-95.

7. Hogan SF, Ireland K. Fatal acute spontaneous endometritis resulting from Clostridium sordellii. Am J Clin Path 1989;91:104-6.

8. Browdie DA, Davis HJ, Koplewitz MJ, Corday L, Leadbetter AW. Clostridium sordellii infection. J Trauma 1975;15:515-9.

9. Martinez OV, Malinin TI. The effect of postmortem interval and manner of death on blood and bone marrow cultures from non-septic cadaver donors of tissues for transplantation. Abstracts 96th Meeting, American Society for Microbiology. C-84, New Orleans, 1999;16.

10. Martinez OV, Malinin TI, Valla PH, Flores A. Postmortem bacteriology of cadaver tissue donors: an evaluation of blood cultures as an index of tissue sterility. Diag Microbiol Infect Dis 1985;3:193-200.

11. Hornicek FJ, Wall JE, Kasprisin D, eds. Standards for tissue banking McLean, VA: 10th edn. American Association of Tissue Banks, 2002.

12. du Molin G, Love W. The value of autopsy microbiology. Clin Microbiol Newsletter 1988;10:165-167.

13. Koneman E, Davis M. Postmorten bacteriology. 3. The significance of microorganisms recovered at autopsy. Am J Clin Pathol 1974;61:28-40.

14. du Molin GC, Paterson DG. Clinical relevance of postmortem microbiologic examination: a review. Hum Path 1985;16:539-48.

15. Roberts FJ. Procurement, interpretation, and value of postmortem cultures. Eur J Clin Microbio Infect Dis 1998;17:821-7.

16. Malinin TI. Acquisition and banking of bone allografts. In Habal MB, Reddi AH, eds. Bone grafts and bone substitutes. Philadelphia: WB Saunders, 1992:206-225.

17. Malinin TI, Martinez OV, Brown MD. Banking of massive osteoarticular allografts: 12 years' experience. Clin Orthop 1985;197:44-57.

18. Kreutz FP, Hyatt GW, Turner TC, Bassett AJ. The preservation and clinical use of freeze-dried bone. JBJD 1951;33A:863-872.

19. Malinin TI. University of Miami Tissue Bank: collection of postmortem tissues for clinical use of laboratory investigation. Transplant Proc 1976;8(suppl 1):53-8.

20. Buck BE, Malinin TI. Human bone and tissue and allografts, preparation and safety. Clin Orthop 1994;303:8-17.

21. Malinin T. Allografts for the reconstruction of the cruciate ligaments of the knee: procurement, sterilisation and storage. Sports Med Arthroscopy Rev 1993;1:31-41.

22. Brook I. Anaerobic bacterial bacteremia: 12-year experience in two military hospitals. J Infec Dis 1989;160:1071-5.

23. Martinez OV, Buck BE, Hernandez M, Malinin TI. Blood and marrow cultures as indicators of bone contamination in cadaver donors. Clin Orthop 2003;409:317-24.

24. Malinin T, Buck BE, Temple HT. Allografts: risks of infection. Cur Op Orthop 2002;13:440-2. 